\title{
Mapping of stripe rust resistance QTL in Cappelle- Desprez $\times$ PBW343 RIL population effective in northern wheat belt of India
}

\author{
Sushma Kumari Pawar ${ }^{1}$ Davinder Sharma ${ }^{1}$ Joginder Singh Duhan ${ }^{2} \cdot$ \\ Mahender Singh Saharan ${ }^{1} \cdot$ Ratan Tiwari $^{1} \cdot$ Indu Sharma $^{1}$
}

Received: 9 April 2015/Accepted: 8 October 2015/Published online: 16 February 2016

(C) The Author(s) 2016. This article is published with open access at Springerlink.com

\begin{abstract}
Stripe rust caused by Puccinia striiformis f. sp. tritici is most important and devastating disease of wheat worldwide, which affects the grain yields, quality and nutrition. To elucidate, the genetic basis of resistance, a mapping population of recombinant inbred lines was developed from a cross between resistant Cappelle-Desprez and susceptible cultivar PBW343 using single-seed descent. Variety PBW343 had been one of the most popular cultivars of North Western Plains Zone, for more than a decade, before succumbing to the stripe rust. CappelleDesprez, a source of durable adult plant resistance, has maintained its resistance against stripe rust for a long time in Europe. Map construction and QTL analysis were completed with 1012 polymorphic (DArT and SSR) markers. Screenings for stripe rust disease were carried out in field condition for two consecutive crop seasons (2012-2013 and 2013-2014). Susceptible parent (PBW343) achieved a significant level of disease i.e., $100 \%$ in both the years. In present investigations, resistance in Cappelle-Desprez was found stable and response to the rust ranged from 0 to $1.5 \%$ over the years. The estimated broad-sense heritability $\left(h^{2}\right)$ of stripe rust rAUDPC in the mapping population was 0.82 . The relative area under the disease progress curve data showed continuous distributions, indicating that trait was controlled multigenically. Genomic region identified on chromosome $2 \mathrm{D}$, was located within the short arm, with flanking markers (Xgwm484-Xcfd73), explained phenotypic
\end{abstract}

Ratan Tiwari

tiwari1964@yahoo.com

1 Indian Institute of Wheat and Barley Research, Karnal 132001, India

2 Ch. Devi Lal University, Sirsa, Haryana 125055, India variation (PVE) ranged from 13.9 to $31.8 \%$. The genomic region identified on chromosome $5 \mathrm{~B}$ was found with the effect of maximum contribution with flanking DArT markers (1376633|F|0-1207571|F|0), PVE ranged from 24 to $27.0 \%$. This can, therefore, be utilized for marker assisted selection in developing much needed stripe rust resistant lines for the northern wheat belt of India.

Keywords Stripe rust - QTL mapping - Adult plant resistance $\cdot$ DArT markers

\section{Introduction}

Stripe rust caused by Puccinia striformis is one of the major biotic constraints of wheat production in areas where the cool temperature prevails and affects the grain yield, quality and nutrition. Stripe rust is one of the most important diseases that can cause tremendous losses in wheat production worldwide (Stubbs 1988). Stripe rust can cause yield losses up to 10-70 \% and in some cases as high as $100 \%$ yield loss, if the infection occurs at a very early stage and continues to the later stage of the plants (Syed et al. 2007). Major wheat producing area in India fall under North Western Plains Zone (NWPZ) along with the strategic area of wheat cultivation under Northern Hills Zone (NHZ). The disease can be controlled by the use of chemicals, although this method is neither cost effective nor environmentally safe (Rosewarne et al. 2013). Other important effective strategy to control disease is the use of resistant cultivars and the deployment of resistance gene in high yielding varieties. Resistance could be either race specific or non-race specific. Race-specific, also called vertical/seedling/non-durable type of resistances often when deployed is effective only for short-time period 
(4-5 years). Generally, it is overcome by the new races of pathogen because of constant evolution/selection of races in the nature. On the other hand, non-race-specific resistance (horizontal/partial/slow-rusting/durable or adult plant resistances) shows pleiotropic effect is hard to match by the pathogen and can combat the disease for wide range of pathotypes. A number of such type of slow-rusting genes (showing additive effect) need to be pyramided together to achieve effective genetic control against disease progress in the field. Some of the durable/slow-rusting genes namely Lr34/Yr18, Lr46/Yr29, Lr67/Yr46 and Sr2/Yr30 have been reported and found effective in providing rust resistance at field level (Rosewarne et al. 2012). Therefore, it is necessary to search for new source(s) of resistance to identify durable adult plant effective stripe rust resistance against the evolving pathotypes in bread wheat.

Various molecular markers have been widely used to tag and map resistance genes in wheat; however, simple sequence repeat (SSR) has emerged as the choice of marker in gene mapping studies. The development of GBS molecular marker technology that leads to an easy genotyping of large complex genome size such as wheat results in production of detailed genetic map. High throughput markers are not well integrated into the maps, which is the major problem regarding its usage. So, with the help of SSR markers it is easy to locate the positions of different marker types (SNP and DArT) and can build consensus maps between different marker systems. Numerous QTLs (over 140) for resistance to stripe rust in wheat have been reported and through mapping of flanking markers on consensus maps, 49 chromosomal regions have been identified (Rosewarne et al. 2013).

Cappelle-Desprez (European cultivar) was first released in France in 1946 (Lupton and Macer 1962; Worland and Law 1986; Bonjean et al. 2001). It contains seedling resistance genes $\mathrm{Yr} 3 a$ and $\mathrm{Yr} 4 a$ (De Vallavieille-Pope et al. 1990), but presence of APR against stripe rust in this cultivar is less reported. Cappelle-Desprez maintained a high level of resistance so that it is still recognized as a good source of APR in many European countries.

The objective of the present study was to identify genomic regions controlling adult plant resistance (APR) to stripe rust in recombinant inbred line (RIL) population developed from the cross of 'Cappelle-Desprez' (resistant) with 'PBW343' (susceptible) parents.

\section{Methods}

\section{Development and evaluation of RILs}

This work was conducted at the Indian Institute of Wheat and Barley Research (IIWBR), Karnal $\left(29^{\circ} 41^{\prime} 0^{\prime \prime} \mathrm{N}\right.$, $76^{\circ} 59^{\prime} 0^{\prime \prime} \mathrm{E}$ ) during the two consecutive crop seasons 2012-2013 and 2013-2014, under field condition. A mapping population of $88 \mathrm{~F}_{9}$ recombinant inbred lines (RILs) was developed from a cross between resistant Cappelle-Desprez (Vilmorin-27/Hybride-du-Joncquois) and susceptible cultivar PBW343 (ND/VG9144//KALBB/ 3/YCO "S"/4A/EE\#S "S") using single-seed descend method. The population was further advanced up to $F_{9}$ generations through selfing.

\section{Stripe rust response test}

\section{Adult plant stripe rust response test}

Planting was done in the first week of November in a randomized complete block design (RCBD) with two replications. About 20 seeds from each line were planted in $1 \mathrm{~m}$ row with $20 \mathrm{~cm}$ space, comprising two rows in each replication. Susceptible check wheat variety 'Agra local' was planted after every 9th plot to ascertain the uniformity of infection throughout the field. Urediniospore-watertween 20 suspension with stripe rust pathotype 46S119 was atomized at Z12-Z14 Zadok secondary growth stage (Zadoks et al. 1974) according to the National Plant protection Standard ( $\mathrm{Li}$ et al. 1989). Urediniospores were collected from the actively sporulating plants of susceptible varieties maintained in isolation in polyhouse. Disease severity (DS) data were recorded at weekly interval, for four observations. The disease severity for each line was evaluated for the crop season 2012-2014, under field condition according to the modified Cob Scale (Peterson et al. 1948).

\section{Molecular marker analysis}

Genomic DNA was isolated from leaf sample at two leaf stage using DArT protocol (https://www.diversityarrays. com). Genotyping was done on 88 lines, including the parents with 26, 206 Diversity Array Technologies (DArT) markers by Triticarte Pty Ltd. (Canberra, Australia) and 50 SSR markers located specifically on chromosome 2D and 5B chromosomes (Appels 2003). A total of 1012(962 DArT and $50 \mathrm{SSR}$ ) markers found polymorphic between the parents were used to find the linkage groups. The PCR was done on a thermocycler (BioRad, USA S-1000) with protocol consisting of an initial denaturation at $94{ }^{\circ} \mathrm{C}$ for $5 \mathrm{~min}$, followed by 35 cycles of denaturation at $94{ }^{\circ} \mathrm{C}$ for $1 \mathrm{~min}$; annealing at $50-60{ }^{\circ} \mathrm{C}$ (depending on the individual microsatellite primer) for $1 \mathrm{~min}$; and extension at $72{ }^{\circ} \mathrm{C}$ for $1 \mathrm{~min}$ followed by a 6 min final extension at $72{ }^{\circ} \mathrm{C}$. Amplification products were resolved by electrophoresis on $3 \%$ agarose gels, visualized by ethidium bromide staining, and gel photograph taken by Geldoc system (Syngene Ltd., USA). 


\section{Statistical analysis}

Disease severity data were used to calculate the area under the disease progress curve (AUDPC) for each line and the parent according to the formula,

$\mathrm{AUDPC}=\sum\left[\left(Y_{i}+Y_{(i+1)}\right) / 2\right]\left(t_{(i+1)}-t_{i}\right)$,

where $Y_{i}=$ disease severity value on date $t_{i}, t_{(i+1)}-t_{i}=$ time (days) between two disease scores $n=$ number of times when disease was recorded (Duveiller et al. 1998; Joshi and Chand 2002). The relative AUDPC values were used for the subsequent analysis of variance (ANOVA) and QTL analysis (Lin and Chen 2007). ANOVA was performed using the $\operatorname{SAS}^{\circledR} 9.3$ statistical package (SAS Institute, Cary, NC, USA).

Broad-sense heretability $\left(h^{2}\right)$ of phenotypic trait (rAUDPC) was calculated using the formula

$h^{2}=\sigma_{\mathrm{G}}^{2} /\left[\left(\sigma_{\mathrm{G}}^{2}+\sigma_{\mathrm{GE}}^{2} / e+\sigma_{\mathrm{E}}^{2} /(e \times r)\right)\right]$,

where $\sigma_{\mathrm{G}}^{2}, \sigma_{\mathrm{GE}}^{2}$ and $\sigma_{\mathrm{E}}^{2}$ are estimates of genotypic, genotypic $\times$ environment interaction and error variances, respectively, and $e$ and $r$ are the numbers of environments and replications per environment, respectively (Yang et al. 2005).

Chi test for goodness-of-fit to the expected 1:1 was analyzed for the segregation of individual markers. Polymorphic marker loci exhibiting significant distortion from these expected 1:1 segregation ratios were discarded from the linkage analysis. Chi-square analysis of observed against expected frequencies for disease severity classes was calculated with the "Chi test" function in Microsoft office 2007 Excel. $\chi^{2}=\sum(\text { Observed value }- \text { Expected value })^{2} /($ Expected value), where degree of freedom $(d f)=n-1$.

Genetic linkage groups were performed using "MapDisto" Version 1.7 beta software (http://mapdisto.free.fr; Lorieux 2007). Further, grouped markers position was estimated using Join map 4.1 (Van Ooijen 2006). QTL analysis was performed using polymorphic markers falling in a particular linkage group and rAUDPC of the RIL population using composite interval mapping (CIM) with WinQTL Cart V2.5 (Wang et al. 2011). For CIM, significant logarithm of odds (LOD) thresholds was estimated by conducting a permutation test with 1000 interactions at $P=0.05$ (Fig. 1)

\section{Results}

\section{Field assessment of stripe rust resistance}

The field studies showed a significance level of disease within the population in both the years (Table 2). Stripe rust severity for the susceptible parent was $100 \%$; the resistance in Cappelle-Desprez was stable across the years and response to the rust ranged from 0 to $1.5 \%$ over the years.
Relative area under disease progress curve (rAUDPC) was calculated from the stripe rust scoring for both crop seasons. No significant differences were detected among replications; and RILs were the only significant source of phenotypic variation observed in the study and interaction between genotype $\times$ year was significant; therefore, ANOVA was performed separately for both the years (Table 3). Relative AUDPC during 2012-2013 ranged from 0 to 116.5 with an average of 46.1 . For the year 2013-2014, the range of rAUDPC was 1.5-98.5 and mean value was 39.1. The value of standard error (SE) was obtained as 1.0 at $5 \%$ LSD value as shown in Table 2. The estimated broadsense heritability $\left(h^{2}\right)$ of stripe rust rAUDPC in the mapping population was 0.82 . Phenotypic classification for both the years (2012-2013 and 2013-2014) showing transgressive segregation has been given in the Fig. 2a, b.

\section{Mapping and QTL analysis}

A genetic linkage map was constructed using 50 SSR (18.8\%) along with 962 (3.6\%) polymorphic markers between parents Cappelle-Desprez and PBW343. Twentysix linkage groups were identified which covered almost all the 21 chromosomes of Wheat. Identified these two groups representing chromosome $2 \mathrm{D}$ and $5 \mathrm{~B}$ containing at least 2 or more SSR loci's on each. Linkage groups 2D and 5B covered a total map distance of $248 \mathrm{cM}$.

Linkage groups $2 \mathrm{D}$ and 5B containing a total of $11 \mathrm{SSR}$ and 2 SSR + 12 DArT markers covered a map distance of 95 and $153 \mathrm{cM}$, respectively. Identified two linkage groups were used for QTL analysis using rAUDPC data. QTL mapping using CIM method of WinQTL Cart V2.5 was detected QTL for adult plant stripe rust response variation on chromosome $2 \mathrm{D}$ and 5B. A LOD score 2.5 was considered as a significant value to detect a QTL.

Subsequent QTL analysis in the mapping population 'Cappelle-Desprez $\times$ PBW343' led to the identification of two QTLs (QYr.iiwbr-5B and QYr.iiwbr-2D) was detected separately and also with mean values of rAUDPC for both the years i.e., 2012-2013 and 2013-2014 (Table 1). The LOD value of rAUDPC for the above years ranged from 3.0 to $3.8 \& 3.5$ to 6.0 , respectively while their corresponding phenotypic variation (PVE) ranged from 13.9 to 31.8 and 24.0 to $27.0 \%$, respectively. QYr.iiwbr-5B conferring with maximum contribution to stripe rust resistance was flanked by DArT markers 1376633|F|0-1207571|F|0 peaks located with $X W m c 745$ marker. A minor QTLeffect showed on the short arm of chromosome 2D (QYr.iiwbr$2 D)$ to stripe rust with flanking marker loci Xgwm484$X c f d 73$. The stripe rust resistance QTLs mapped, their chromosomal location, flanking markers and explained phenotypic variance (PVE) based on composite interval mapping is summarized in Table 1 . 

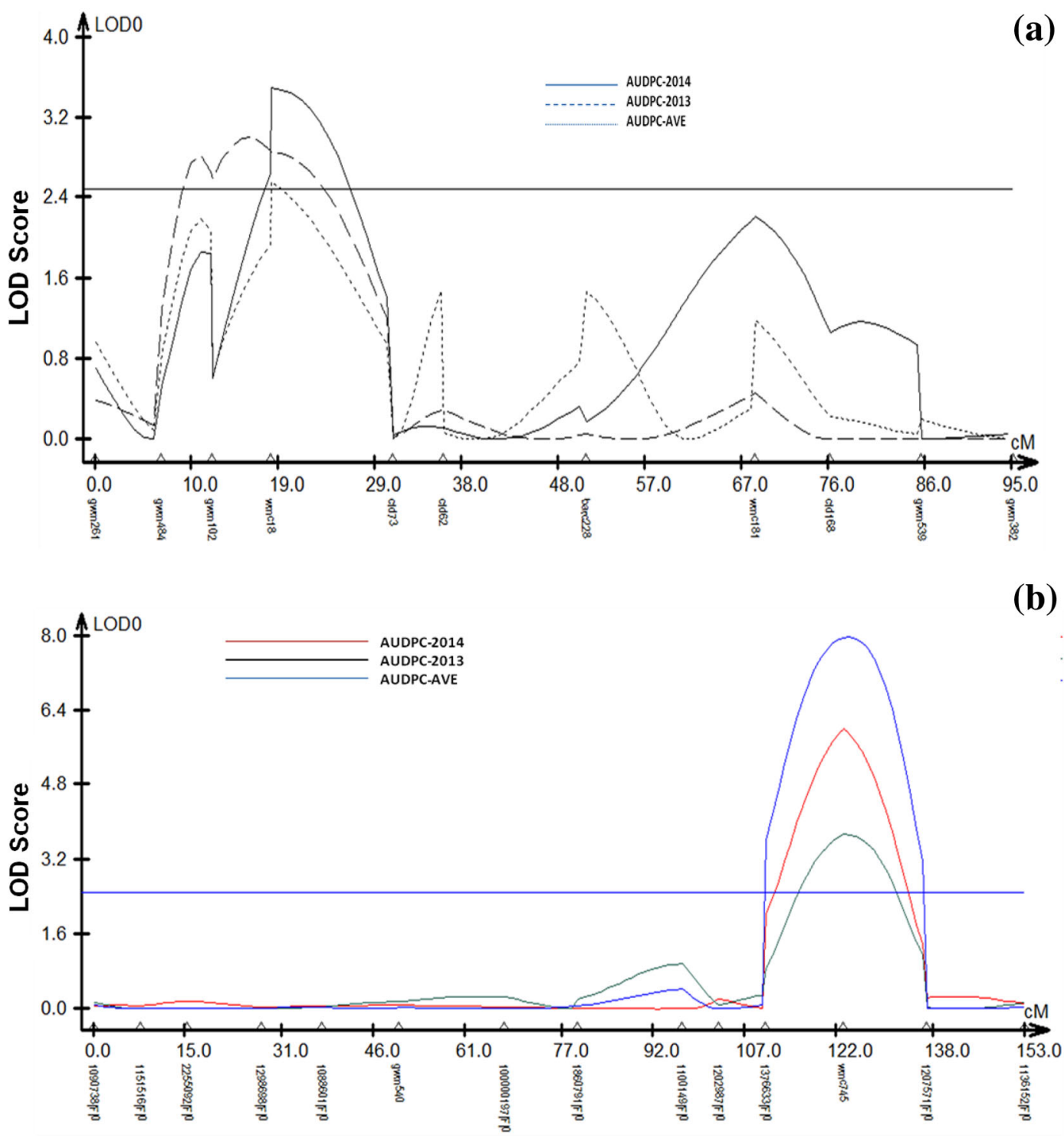

Fig. 1 Composite interval mapping of stripe rust severity at adult plant stage in the Cappelle-Desprez/PBW343 mapping population based on stripe rust screening for 2014 and 2013. QTLs were detected on chromosome 2D (a) and 5B (b) with significant LOD scores

Adult plant effective genomic regions for stripe rust were identified during the present study. Chromosome $2 \mathrm{D}$ and $5 \mathrm{~B}$ carried genes which were found effective for stripe rust pathotype prevalent under the field conditions. These genomic regions were found to be effective for Indian isolates of stripe rust. These genomic regions identified in the present study can be exploited for enhancing the stripe rust resistance in the wheat cultivars through marker assisted selection (Tables 2, 3).

\section{Discussion}

Stripe rust severity for the susceptible parent (PBW343) achieved a significant level of disease i.e., $100 \%$ in both the years. In India, PBW343 had been one of the most popular and ruling varieties of North Western Plains Zone (NWPZ). Lines PBW343 and Inqualab 91 along with their derivatives not only carried high levels of resistance to leaf and stripe rusts or both, but also showed about 5-15\% higher yield potential than the original cultivars (Singh et al. 2004). Stripe rust resistance in PBW343 (in India), Inquilab-91 and Bakhtwar (in Pakistan), Chamran and Shiroudi (in Iran), Kubsa (in Ethiopia) and Cham 8 (in Syria) was based on $Y r 27$. Breakdown of $Y r 27$ resistance in PBW343, Inquilab 91 and Chamran, in India, Pakistan and Iran, respectively, was reported between 2002 and 2004. Although occasional stripe rust outbreaks appeared in some other wheat growing areas of the world as well but due to unfavorable environmental conditions increase in the severity of $Y r 27$ virulent pathotypes got restricted. 

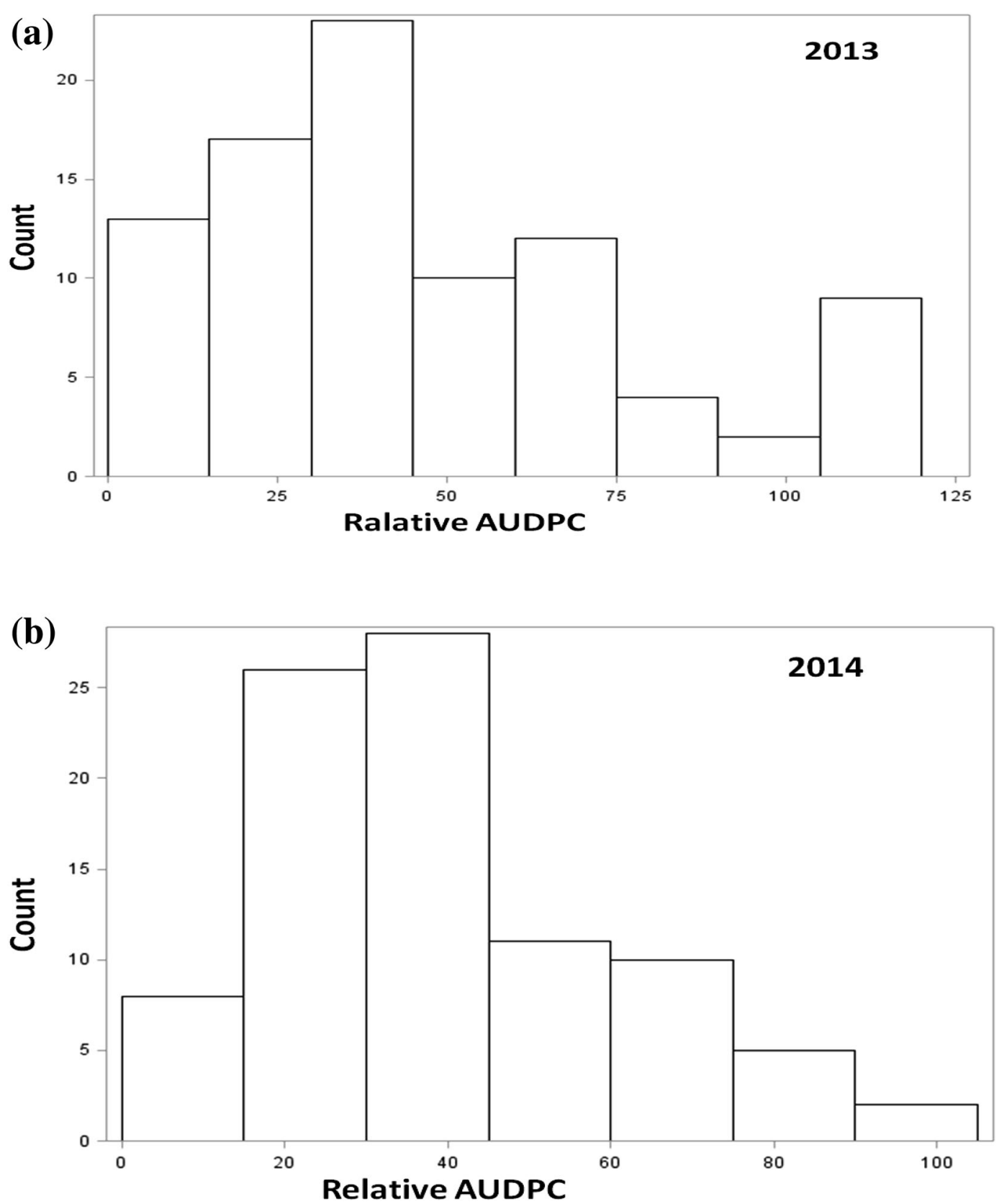

Fig. 2 Frequency distribution of relative area under the disease progress curve (rAUDPC) for $88 \mathrm{~F}_{9}$ recombinant inbred lines (RILs) for adult plant resistance to stripe rust for year 2013 and 2014

In present investigation resistance in Cappelle-Desprez was found stable and response to the rust ranged from 0 to $1.5 \%$ over the years. Cappelle-Desprez (European cultivar) was first released in France and due to its resistance to stripe rust it occupied a large acreage across Western Europe for a very long duration, until the late 1970s (Bonjean et al. 2001). Worland and Law (1986) and Law and Worland (1997) reported high level of APR for number of major diseases, including stripe rust as a main reason of longevity of this cultivar. Due to the longevity of this cultivar, it was extensively used in many breeding programmes such as UK and in many European countries (Angus 2001; Bonjean et al. 2001; Porche 2001). CappelleDesprez although known for having seedling resistance genes $\mathrm{Yr} 3 a$ and $\mathrm{Yr} 4 a$ (De Vallavieille-Pope et al. 1990), also maintained a high level of resistance in many European countries due to its adult plant resistance.

Present study leads to the identification of QYr.iiwbr-5B on short arm of chromosome 5B with flanking DArT markers (1376633|F|0-1207571|F|0), peak located with 
Table 1 Identification of significant (LOD > 2.5) QTL for stripe rust resistance, their chromosomal location, flanking markers and explained phenotypic variance $\left(R^{2}\right)$ based on composite interval mapping in Cappelle-Desprez $\times$ PBW 343 population

\begin{tabular}{|c|c|c|c|c|c|c|}
\hline Year & QTL & Marker interval & LOD & Interval size (cM) & PVE $(\%)$ & Add \\
\hline \multirow[t]{2}{*}{2013} & QYr.iiwbr-5B & 1376633|F|0-1207571|F|0 & 3.8 & 26.4 & 31.8 & 16.6 \\
\hline & QYr.iiwbr-2D & Xgwm484-Xcfd73 & 3.0 & 34.7 & 13.9 & 12.7 \\
\hline \multirow[t]{2}{*}{2014} & QYr.iiwbr-5B & 1376633|F|0-1207571|F|0 & 6.0 & 26.4 & 27.0 & 17.0 \\
\hline & QYr.iiwbr-2D & Xgwm484-Xcfd73 & 3.5 & 34.7 & 24.0 & 7.0 \\
\hline \multirow[t]{2}{*}{ Average } & QYr.iiwbr-5B & 1376633|F|0-1207571|F|0 & 8.0 & 26.4 & 34.1 & 20.2 \\
\hline & QYr.iiwbr-2D & Xgwm484-Xcfd73 & 2.6 & 34.7 & 20.1 & 8.9 \\
\hline
\end{tabular}

Table 2 Range, mean, $5 \%$ LSD and standard error for trait stripe rust in the population

\begin{tabular}{lccccc}
\hline Trait & Year & Range & Mean & $5 \%$ LSD & Error \\
\hline AUDPC & 2013 & $0-116.5$ & 46.1 & 2.8 & 1.0 \\
& 2014 & $1.5-98.5$ & 39.1 & \\
\hline
\end{tabular}

Table 3 Variance components of relative area under the disease progress curve of the $\mathrm{F}_{9}$ recombinant inbred line population derived from Cappelle-Desprez/PBW343

\begin{tabular}{|c|c|c|c|c|}
\hline Source of variation & $d f$ & Mean square & $F$ value & $P>F$ \\
\hline \multicolumn{5}{|l|}{2014} \\
\hline Gen & 87 & 919.01679 & 12.17 & $<0.0001$ \\
\hline Rep & 1 & 9.33889 & 0.12 & $0.7260^{\mathrm{NS}}$ \\
\hline Error & & 75.54114 & & \\
\hline \multicolumn{5}{|l|}{2013} \\
\hline Gen & 87 & 1975.7017 & 780.71 & $<0.0001$ \\
\hline Rep & 1 & 0.2722 & 0.11 & $0.7437^{\mathrm{NS}}$ \\
\hline Error & & 2.5306 & & \\
\hline
\end{tabular}

XWmc745 marker explaining $34.1 \%$ phenotypic variation with mean rAUDPC value. Mallard et al. (2005) identified two QTL (QYr. inra-5B.1 and QYr. inra-5B.2) with SSR loci Xgwm544 in Camp Remy which mapped to the telomeric region on the long arm of chromosome 5B.

Riley et al. (1967) and Badaeva et al. (2007) reported that Cappelle-Desprez carries the reciprocal, centromeric translocations 5BL-7BL and 5BS-7BS. Its parentage (vilmorin and Hybride du Joncquois) also possesses this translocation (Worland and Law 1986; Law and Worland 1997). Boukhatem et al. (2002), however, in their study, did not identify any QTL on chromosome 5B in Camp Remy. Stripe rust resistance QTL on chromosome 5B have also been detected in the Italian cvs Libellula and Strampelli (Lu et al. 2009), the Israeli cv. Oligoculm (Suenaga et al. 2003), the Australian cv. Janz (Bariana et al. 2010) and the French cv. Flinor (Feng et al. 2011). Feng et al. (2011) identified two QTLs on chromosome 5B which are expressed at the seedling stage and at higher temperatures (QYr-tem-5B.1 and QYr-tem-5B.2) in Flinor. Flinor has ancestral relationship with Cappelle-Desprez and one of these QTL, $Q Y$ r-tem-5B.1, overlaps with the region defining QYr.ufs-5B. QYr-tem-5B.1 explained up to $33 \%$ of the phenotypic variation in Flinor.

Present investigation, also, mapped a minor QTL region on chromosome 2D with significant LOD value. QYr.iiwbr$2 D$, although defined by a smaller marker interval with flanking SSR markers (Xgwm102-Xcfd73), was found contributing less significantly to the explained phenotypic variance i.e., $20.1 \%$ with rAUDPC mean value of both the years. Mallard et al. (2005) identified a QTL (QYr.inra$2 D S$ ) near to the centromere on 2DS in the cv. Camp Rémy between marker loci Xgwm102 and Xgwm539 explaining 24-69\% phenotypic variance, although the reason for explained low phenotypic variance may be probably due to differences in environmental conditions or influenced by genetic background.

Worland and Law (1986) and Worland et al. (1988) suggested that $\mathrm{Yr} 16$, gene is located on the centromeric region of chromosome $2 \mathrm{D}$ and this was further confirmed through cytogenetic analysis. Devos et al. (1993) and Agenbag et al. (2012) placed the gene $9.3 \mathrm{cM}$ from the 
centromere between RFLP marker loci Xpsr641-2D and Xpsr681-2D on a consensus map, Ta-Gale-2D (http:// wheat.pw.usda.gov/GG2/index.shtml).

Bariana et al. (2001) reported temperature-sensitive seedling resistance, $\mathrm{YrCK}$ on chromosome 2D in the Australian cv. Cook and a derivative, cv. Sunco explaining $13-19 \%$ of the phenotypic variance for stripe rust and 9-13\% of the phenotypic variance for leaf rust resistance (Navabi et al. 2005). QYr.caas-2DS, explaining 8.4-12.1\% of the phenotypic variance, was identified in the Italian cv. Libellula, (Lu et al. 2009), while Suenaga et al. (2003) detected QTL explaining less than $10 \%$ of the phenotypic variance in the cv. Oligoculm in this region on 2DS. Stripe rust resistance QTL were identified and mapped on the short arm of chromosome 2D, close to the QYr.ufs- $2 D$ in the UK cvs Guardian (Melichar et al. 2008) and Claire (Powell 2010), both of which have Cappelle-Desprez in their pedigrees.

Present investigation confirms the effectiveness of genomic regions on chromosome $2 \mathrm{D}$ and $5 \mathrm{~B}$ for stripe rust pathotypes in our population in Indian conditions. These may be exploited for enhancing the level of resistance against stripe rust in the cultivated wheat germplasm through marker assisted selection.

Acknowledgments This is an outcome of the Project DWR/RP/105.1. Authors acknowledge ICAR-IIWBR for providing logistics for running the project. Assistance of Ms. SuchetaNegi, Dr. Girish Chandra Pandey and Dr. Ajay Verma is also acknowledged.

\section{Compliance with ethical standards}

Conflict of interest The authors declare that they have no conflict of interest.

Open Access This article is distributed under the terms of the Creative Commons Attribution 4.0 International License (http:// creativecommons.org/licenses/by/4.0/), which permits unrestricted use, distribution, and reproduction in any medium, provided you give appropriate credit to the original author(s) and the source, provide a link to the Creative Commons license, and indicate if changes were made.

\section{References}

Agenbag GM, Pretorius ZA, Boyd LA, Bender CM, Prins R (2012) Identification of adult plant resistance to stripe rust in the wheat cultivar Cappelle-Desprez. Theor Appl Genet 125:109-120. doi:10.1007/s00122-012-1819-5

Angus WJ (2001) United Kingdom wheat pool. In: Bonjean AP, Angus WJ (eds) The world wheat book. A history of wheat breeding. Lavoisier Publishing, Paris, pp 103-126

Appels R (2003) A consensus molecular genetic map for wheat-a cooperative international effort. In: Progna N (ed) Proceedings of the 10th international wheat genetics symposium. Paestum, Italy, pp 211-214

Badaeva ED, Dedkova OS, Gay G, Pukhalskyi VA, Zelenin AV, Bernard S, Bernard M (2007) Chromosomal rearrangements in wheat: their types and distribution. Genome 50:907-926
Bariana HS, Hayden MJ, Ahmed NU, Bell JA, Sharp PJ, McIntosh RA (2001) Mapping of durable adult plant and seedling resistance to stripe rust and stem rust diseases in wheat. Aust J Agric Res 52:1247-1255

Bariana HS, Bansal UK, Schmidt A, Lehmensiek A, Kaur J, Miah H, Howes N, McIntyre CL (2010) Molecular mapping of adult plant stripe rust resistance in wheat and identification of pyramided QTL genotypes. Euphytica 176:251-260

Bonjean AP, Doussinault G, Stragliati J (2001) French wheat pool. In: Bonjean AP, Angus WJ (eds) The world wheat book. A history of wheat breeding. Lavoisier Publishing, Paris, pp 128-165

Boukhatem N, Baret PV, Mingeot D, Jacquemin JM (2002) Quantitative trait loci for resistance against yellow rust in two wheatderived recombinant inbred line populations. Theor Appl Genet 104:111-118

De Vallavieille-Pope C, Picard-Formery H, Radulovic S, Johnson R (1990) Specific resistance factors to yellow rust in seedlings of some French wheat varieties and races of Puccinia striiformis west end in France. Agronomie 2:103-113

Devos KM, Millan T, Gale MD (1993) Comparative RFLP maps of the homoeologous group-2 chromosomes of wheat, rye and barley. Theor Appl Genet 85:784-792

Duveiller E, García I, Toledo J, Franco J, Crossa J, Lopez F (1998) Evaluating spot blotch resistance of wheat: improving disease assessment under controlled conditions and in the field. In: Duveiller E, Dubin HJ, Reeves J, Mcnab A (eds) Helminthosporium blights of wheat: spot Blotch and tan Spot. CIMMYT, Mexico, pp 171-181

Feng J, Zuo LL, Zhang ZY, Lin RM, Cao YY, Xu SC (2011) Quantitative trait loci for temperature-sensitive resistance to Puccinia striiformis f. sp. tritici in wheat cultivar Flinor. Euphytica 178:321-329

Joshi AK, Chand R (2002) Variation and inheritance of leaf angle and its relationship with resistance to spot blotch in wheat (Triticum aestivum). Euphytica 124:283-291

Law CN, Worland AJ (1997) The control of adult-plant resistance to yellow rust by the translocated chromosome 5BS-7BS of bread wheat. Plant Breed 116:59-63

Li GB, Zeng SM, Li ZQ (1989) Integrated management of wheat pests. Press of Agriculture Science and technology of China, Beijing, pp 185-186

Lin F, Chen XM (2007) Genetics and molecular mapping of genes for race-specific all-stage resistance and non-race-specific high temperature adult-plant resistance to stripe rust in spring wheat cultivar, Alpowa. Theor Appl Genet 114:1277-1287

Lorieux M (2007) MapDisto Version 1.7 beta for Excel 2007. http:// mapdisto.free.fr/. Accessed February 2009

Lu Y, Lan C, Liang S, Zhou X, Liu D, Zhou G, Lu Q, Jing J, Wang M, Xia X, He Z (2009) QTL mapping for adult-plant resistance to stripe rust in Italian common wheat cultivars Libellula and Strampelli. Theor Appl Genet 119:1349-1359

Lupton FGH, Macer RCF (1962) Inheritance of resistance to yellow rust (Puccinia glumarum Erikss and Henn.) in seven varieties of wheat. Trans Br Mycol Soc 45:21-45

Mallard S, Gaudet D, Aldeia A, Abelard C, Besnard AL, Sourdille P, Dedryver F (2005) Genetic analysis of durable resistance to yellow rust in bread wheat. Theor Appl Genet 110:1401-1409

Melichar JPE, Berry S, Newell C, MacCormack R, Boyd LA (2008) QTL identification and microphenotype characterisation of the developmentally regulated yellow rust resistance in the UK wheat cultivar Guardian. Theor Appl Genet 117:391-399

Navabi A, Tewari JP, Singh RP, McCallum B, Laroche A, Briggs KG (2005) Inheritance and QTL analysis of durable resistance to stripe and leaf rusts in an Australian cultivar, Triticum aestivum 'Cook'. Genome 48:97-107

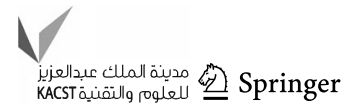


Peterson RF, Campbell AB, Hannah AE (1948) A diagrammatic scale for rust intensity on leaves and stems of cereals. Can J Res 26:496-500

Porche W (2001) German wheat pool. In: Bonjean AP, Angus WJ (eds) The world wheat book. A history of wheat breeding. Lavoisier Publishing, Paris, pp 168-191

Powell NM (2010) Phenotyping and genetic analysis of yellow rust resistance in the UK winter wheat cultivar Claire. Dissertation, University of East Anglia

Riley R, Coucoli H, Chapman V (1967) Chromosomal interchanges and the phylogeny of wheat. Heredity 22:233-247

Rosewarne GM, Singh RP, Huerta-Espino J, Herrera-Foessel SA, Forrest KL, Hayden MJ, Rebetzke GJ (2012) Analysis of leaf and stripe rust severities reveals pathotype changes and multiple minor QTLs associated with resistance in an Avocet 3 Pastor wheat population. Theor Appl Genet 124:1283-1294

Rosewarne GM, Herrera-Foessel SA, Singh RP, Huerta-Espino J, Lan CX, He ZH (2013) Quantitative trait loci of stripe rust resistance in wheat. Theor Appl Genet 126:2427-2449

Singh RP, William HM, Huerta-Espino J, Rosewarne G (2004) Wheat rust in Asia: meeting the challenges with old and new technologies. Proceedings of the 4th international crop science congress, Brisbane, Australia

Stubbs RW (1988) Pathogenicity analysis of yellow (stripe) rust of wheat and its significance in a global context. In: Simmonds
NW, Rajiaram S (eds) Breeding strategies for resistance to the rusts of wheat. CIMMYT, Mexico, pp 23-28

Suenaga K, Singh RP, Huerta-Espino J, William HM (2003) Microsatellite markers for genes Lr34/Yr18 and other quantitative trait loci for leaf rust and stripe rust resistance in bread wheat. Phytopathology 93:881-890

Syed NA, Haque ML, Ahmedi MS, Samina B, Rattu AR (2007) Assessment of yield losses caused by Puccinia striiformis triggering stripe rust in the most common wheat varieties. Pak J Bot 39(6):2127-2134

Van Ooijen JW (2006) JoinMap 4. Soft ware for the calculation of geneticlinkage maps in experimental populations. Kyazma B.V., Wageningen

Wang S, Basten CJ, Zeng ZB (2011) Windows QTL Cartographer 2.5. Department of Statistics, North Carolina State University, Raleigh, NC. http://statgen.ncsu.edu/qtlcart/WQTLCart.htm

Worland AJ, Law CN (1986) Genetic analysis of chromosome 2D of wheat. Z Pflanzenzücht 96:331-345

Worland AJ, Petrovic S, Law CN (1988) Genetic analysis of chromosome 2D of wheat. Plant Breed 100:247-259

Yang J, Bai G, Shaner GE (2005) Novel quantitative trait loci (QTL) for Fusarium head blight resistance in wheat cultivar Chokwang. Theor Appl Genet 111:1571-1579

Zadoks JC, Chang TT, Konzak CF (1974) A decimal code for the growth stages of cereals. Weed Res 14:415-421 